\title{
Otite externa necrotizante com paralisia facial periférica bilateral : relato de caso e revisão da literatura
}

\section{Necrotizing external otitis with periferic bilateral facial palsy: case report and literature review}

Palavras-chave: otite, otite externa necrotizante, paralisia facial.

Key words: otitis, necrotizing external otitis, facial palsy.

\section{Resumo / Summary}

\begin{abstract}
A
otite externa necrotizante (OEN), conhecida no passado como otite externa maligna, é uma infecção potencialmente letal que começa usualmente no conduto auditivo externo e se estende à base do crânio ocorrendo, principalmente, em pacientes diabéticos idosos e que a despeito de antibioticoterapia prolongada está associada à morbidade elevada e mortalidade significante. Os autores apresentam o caso de um paciente adulto, diabético, com OEN e paralisia facial periférica bilateral que evoluiu com cura da infecção, porém sem melhora da paralisia.
\end{abstract}

ecrotizing external otitis (NEO), known in the past as malignant external otitis, is a potencial letal infection which begins usually in the external ear canal and spreads to the base of the skull. It occurs mainly in diabetic elderly patients who despite prolonged antibioticotherapy is associated to high morbidity and significant mortality. The authors present a case of an adult diabetic patient who developed NOE associated with bilateral periferic facial palsy evoluting with cure of the infection but without facial improvement.

\footnotetext{
${ }_{1}^{1}$ Professor Substituto (Mestre em Cirurgia) e Preceptor do Departamento de O torrinolaringologia do HC-UFPE.

${ }^{2}$ Professor Substituto do Departamento de Otorrinolaringologia do HC-UFPE. ${ }_{3}^{3}$ Médico Residente do 30 ano.

${ }^{4}$ Professor Titular do Departamento de Otorrinolaringologia do HC-UFPE. Endereço para Correspondência: Dr. Antonio Antunes - Rua Paissandú 381/1001 Boa Vista Recife PE 50070-200 Tel (0xx81)3432-1270 - Fax (0xx81)343-13667 - E-mail: aantunes@truenet.com.br Trabalho realizado na Disciplina de Otorrinolaringologia da Universidade Federal de Pernambuco e apresentado no 36을 Congresso Brasileiro de Otorrinolaringologia, Florianópolis-SC de 19-23 de novembro de 2002. Artigo recebido em 15 de abril de 2003. Artigo aceito em 05 de junho de 2003.
} 


\section{INTRODUÇÃO}

A otite externa necrotizante (OEN), conhecida no passado como otite externa maligna, é uma infecção potencialmente letal que começa usualmente no conduto auditivo externo e se estende à base do crânio ocorrendo, principalmente, em pacientes diabéticos idosos e que a despeito de antibioticoterapia prolongada está associada à morbidade elevada e mortalidade significante. ${ }^{1}$ Ap resentamos o caso de um paciente adulto, diabético, com OEN e paralisia facial periférica bilateral, que evoluiu com cura da infecção, porém sem melhora da paralisia. 0 primeiro relato de osteomielite do osso temporal foi descrito em Paris por Telmouche em 1838. ${ }^{2}$ Posteriormente, em 1959, Meltzer e Keleman descreveram uma osteomielite do osso temporal, zigoma, mandíbula e base do crânio progressiva causada por Pseudomonas aeruginosa ${ }^{3}$, porém coube a Chandler em 1968 o mérito da descrição precisa desta entidade clínica na sua série original de 13 pacientes, a maioria constituída por diabéticos. ${ }^{4}$

\section{REVSÃO DA LITERATURA}

Como já foi referida, a terminologia inicial desta doença foi otite externa maligna, termo cunhado inicialmente por Chandler, sendo o termo necrotizante introduzido em 1973 por Evans e Richards, fornecendo um termo mais acurado à patologia. Cohn adicionou o termo "progressiva" tendo Doroghazi substituído "necrotizante" por "invasiva". Seria mais interessante que um só nome tivesse permanecido na literatura e sido usado consistentemente. No entanto, as objeções ao termo maligna são bem aceitas, visto que não se trata de doença neoplásica, contudo o termo mais usado ainda hoje é otite externa maligna. Há falta de precisão ainda na utilização dos termos "otite" e "externa" já que a infecção se propaga para planos mais profundos do osso temporal e, portanto, não é apenas uma otite e também não fica restrita apenas ao conduto auditivo externo (CAE). ${ }^{1,5,6}$ 0 agente causador da O EN é na imensa maioria das vezes a Pseudomonas aeruginosa que é um Gram-negativo aeróbio obrigatório não esporogênico e com flagelos polares. ${ }^{7} \mathrm{As}$ cepas mais virulentas produzem uma membrana mucóide que atua como proteção contra fagócitos e antibióticos. Esta camada também é rica em enzimas líticas responsáveis pela vasculite necrotizante típica das infecções por Pseudomonas aeruginosa. Algumas cepas também produzem neurotoxinas que podem provavelmente ter um papel nas neuropatias cranianas periféricas. ${ }^{1,7} \mathrm{~A}$ Pseudomonas aeruginosa pode ser encontrada em cerca de 96 a $98 \%$ de todos os casos de $\mathrm{OEN} .{ }^{8} \mathrm{O}$ utros patógenos podem ser eventualmente identificados como o Aspergillus fumigatus, Proteus mirabilis, Staphylococcus aureus, Staphylococcus epidermidis, Candida albicans, Klebisiella sp. ${ }^{1,6,7,9}$ Já que a Pseudomonas aeruginosa raramente causa infecção em tecidos sãos, mas geralmente progride através de pequenas lesões, tem se atribuído importância, recentemente, ao achado de que mais de $50 \%$ dos casos de OEN são precedidos de manobras (traumáticas e/ ou iatrogênicas no CAE) provocando as referidas lesões. ${ }^{6}$ Inicialmente o processo se limita ao conduto auditivo externo e depois se estende à junção osteo-cartilaginosa do mesmo em direção ao osso temporal. A infecção passa através das fissuras de Santorini no meato externo cartilaginoso para a mastóide. 0 nervo facial (VII par craniano) normalmente é atingido próximo à sua saída no forame estilomastoideo. A infecção pode progredir em direção à base do crânio e afetar os nervos glossofaríngeo (IX par), vago (X par) e acessório (XI par) causando a "síndrome do forame jugular" e eventualmente afetar o nervo hipoglosso (XII par). Menos freqüentemente, os nervos abducente (VI par) e trigêmio (V par) podem ser afetados no ápex petroso. Há um relato de caso em que nervo óptico foi afetado na OEN. ${ }^{1,6,7,10} \mathrm{~A}$ patogênese precisa da OEN é desconhecida. Provavelmente depende da combinação de dois fatores como as alterações subjacentes do sistema imune e as características peculiares da bactéria que poderia encontrar neste ambiente as condições propícias para exercer sua atividade patogênica. Alguns poucos casos de 0 EN são relacionados com outros estados de imunossupressão como doenças hematológicas (leucemia e anemia severa), durante tratamento com drogas citotóxicas ou imunossupressivas, AIDS ou pacientes HIV positivos. ${ }^{11-13} \mathrm{Não}$ se notou nas orelhas dos pacientes diabéticos que sejam mais colonizadas que a dos não diabéticos pela Pseudomonas aeruginosa. 0 quadro clínico inicial não é característico começando freqüentemente semelhante a uma otite externa difusa aguda, o que normalmente retarda o diagnóstico correto e a instituição de terapia adequada. 0 sintoma mais freqüente ( $90 \%$ dos casos) é uma otalgia usualmente lancinante e resistente ao uso de analgésicos que se irradia para as regiões fronto-temporais e parietais piorando à noite. Em $45 \%$ a $100 \%$ dos casos é acompanhada de uma otorréia fétida e purulenta. Há hipoacusia de transmissão leve resultante da obstrução do conduto auditivo externo e de secreção na orelha média. Geralmente, não há sinais sistêmicos como febre ou taquicardia. Sensibilidade e edema peri-auricular são achados comuns. Outro achado freqüente é o tecido de granulação que se localiza no conduto auditivo externo que revela normalmente processo inflamatório crônico inespecífico. Este tecido deve ser biopsiado de rotina, pois apesar de raro pode ser diagnosticado carcinoma espinocelular de orelha externa em alguns pacientes e que clinicamente podem ser indistinguíveis da OEN. .4, $^{15}$ Encontra-se edema e hiperemia do CAE, mas com membrana timpânica usualmente intacta. ${ }^{1,5-7}$ Os sintomas neurológicos associados ocorrem mais freqüentemente como paralisia do VII par craniano e à medida que a doença avança como osteomielite na base do crânio outros pares são atingidos com média geral de 24 a $43 \%$ de pacientes afetados. Há várias complicações que podem sobrevir como abs- 
cesso cerebral, sinusite esfenoidal, aneurisma micótico, parotidite, trombose do seio lateral e sigmóide que são acompanhadas de alta mortalidade. Geralmente as áreas pneumatizadas do osso temporal, a cápsula ótica e labirinto membranoso são poupados. 0 achado laboratorial mais constante e importante é a velocidade de eritrossedimentação, além de hiperglicemia e tolerância reduzida à glicose. Podese encontrar leucocitose moderada. ${ }^{6,7} \mathrm{O}$ s achados radiológicos compreendem radiografia simples de mastóide que pode revelar hipotransparência da pneumatização ou destruição óssea, porém é de pouco utilidade se comparada à tomografia computadorizada (TC). A TC de osso temporal com contraste mostra espessamento de tecidos moles e velamento de mastóide, além de mudanças sutis como erosão da parede do CAE anterior com envolvimento da articulação temporo-mandibular, seqüestro no CAE e erosão da base de crânio ${ }^{5,7} \mathrm{~A}$ Ressonância magnética (RM) pode ser vantajosa para definir a extensão medial da infecção em direção à base do crânio, porém não dá informações sobre os ossos. Devido à persistência das imagens nas TC e RM, mesmo após meses da melhora clínica do paciente foi preciso encontrar outro meio de se avaliar um critério de cura e então se lança mão atualmente de cintigrafias com Tecnécio e Gálio. ${ }^{7}$ A cintigrafia com Tecnécio-99 é útil para o diagnóstico da osteíte. 0 exame é positivo em osteomielite aguda e crônica, bem como em áreas de trauma o que revela sua baixa especificidade. 0 Gálio-67 se incorpora às proteínas e polimorfonucleares nos locais de infecção formando complexos com lactoferrina. Ele mostra o foco de infecção aguda, mas não toda a extensão do processo osteomielítico. À medida que passa o tempo a cintigrafia com Gálio-67 pode voltar ao normal, enquanto a cintigrafia com Tecnécio-99 pode demorar a normalizar. Desta forma recomenda-se estudo inicial dos pacientes com Tecnécio e Gálio e após estudos seqüências com Gálio para monitorizar a respostas à terapia. ${ }^{7} \mathrm{Não}$ existe um critério universalmente aceito para classificar a OEN, porém há três classificações propostas na literatura que são a de Corey et al.; Benecke e a de Levenson et al. Estas levam, basicamente, em conta os diferentes graus de extensão da doença e os achados na cintilografia (Figura 1). .0 diagnóstico é baseado na história clínica, exame físico e exames laboratoriais. Há quatro pontos cardinais no diagnóstico, devendo haver sempre um alto índice de suspeita por parte do clínico para que pacientes não deixem de receber o tratamento agressivo quando apropriado. Os pontos são: 1. Otalgia persistente por mais de um mês; 2 . Otorréia purulenta persistente associada com tecido de granulação por várias semanas; 3. Diabetes mellitus, idade avançada ou outro estado de imunossupressão e 4 . 0 envolvimento de pares cranianos. Deve-se fazer cultura do conduto auditivo externo e freqüentemente é achada a Pseudomonas aeruginosa. Recomenda-se que seja sempre discutido o esquema antibiótico com um infectologista para a escolha final do antibiótico. Na literatura encontramos várias possibilidades como azlocilina e mezlocilina, ceftazidime, imipenem, aztreonam, amicacina, norfloxacina e ciprofloxacina. Usualmente dois antibióticos são associados, sendo um aminoglicosídeo como a gentamicina ou tobramicina (reservando-se a amicacina para cepas resistentes de Pseudomonas) associada a um antibiótico antipseudomonas que é um esquema antigo, porém tem bons resultados. A terapia inicial pode ser alterada dependendo dos resultados das culturas obtidas. Pode ser usada a ticarcilina associada a ácido clavulânico que combina seu efeitoantipseudomonas com

\section{Corey et al. (1985)}

I Infecção do osso e tecidos moles sem envolvimento de nervos cranianos ou lesões intracranianas

II Paralisia de nervos cranianos a) Paralisia do nervo facial isolada b) Paralisia de múltiplos pares

III Meningite, empiema subdural ou extradural e abscesso cerebral

Benecke (1989)

$\begin{array}{lccl} & \text { Ga } 67 & \text { Tc } 99 & \text { Extensão da doença } \\ \text { I } & + & - & \text { Tecidos Moles } \\ \text { II } & + & + & \text { Mastóide / orelha } \\ \text { III } & + & + & \text { Osteomilite extensa }\end{array}$

Levenson etal. (1991)

Pré-OEN Otite externa refratária, otalgia severa, exsudato purulento, tecido de granulação, cultura positiva para $P$. aeruginosa, DM ou outro estrado de imunossupressão com Tc $99 \mathrm{~m}$ negativo

OEN Limitada Todos acima com Tc $99 \mathrm{~m}$ positiva

OEN Central Todos acima com extensão para ATM, base do crânio, espaço parafaríngeo, e fossa infratemporal. E pacientes com envolvimento de pares cranianos.

Figura 1. Classificações propostas para Otite Externa Necrotizante 
atividade contra produtores de beta-lactamase e uma aminoglicosídeo. As desvantagens são os efeitos nefrotóxicos e ototóxicos dos aminoglicosídeos quando utilizados durante um período muito longo. Já os antibióticos antipseudomonas têm possibilidade se causar retenção de sódio, depleção de potássio, hipertransaminasemia, sangramentos espontâneos, anemia hemolítica e convulsões sendo desta forma mandatória uma monitorização cardíaca e restrição da ingesta de sódio. 5,6,7 $\mathrm{O}$ ceftazidime é uma cefalosporina de terceira geração beta-lactamase resistente, bactericida e bastante ativo contra Pseudomonas e outras bactérias Gramnegativas, melhor que as penicilinas antipseudomonas, podendo ser tão eficaz quanto a associação destas com aminoglicosídeos. Pode ser usado isoladamente ou associado a to bramicina e serve para quando há falta na utilização do esquema penicilina antipseudomonas e aminoglicosídeos. A dose preconizada é de $2 \mathrm{~g}$ de $8 / 8 \mathrm{~h}$. Penetra no sistema nervoso central quando existe inflamação. A cefoperazona também é uma cefalosporina de terceira geração com atividade antipseudomonas que também se constitui numa opção válida para tratamento. Podem ser usados também antibióticos beta-lactâmicos como o imipenem e aztreonam que são mais potentes que as penicilinas antipseudomonas e equivalentes às cefalosporinas de terceira geração. A resistência pode se desenvolver durante 0 tratamento contra Pseudomonas se for utilizada em monoterapia o que não acontece com o aztreonam. Este tem uma vantagem adicional porque é bastante seguro em pacientes com alergia às penicilinas. Têm a vantagem de não serem drogas ototóxicas. ${ }^{7}$ Recentemente, alguns pacientes tiveram bons resultados com o uso oral de ciprofloxacina, uma fluorquinolona que atua bem contra Pseudomonas aeruginosa e cujo mecanismo de ação é a inibição da subunidade $A$ da DNA-girase bacteriana (uma enzima envolvida na duplicação do DNA bacteriano). A dose é de $750 \mathrm{mg}$ de $12 / 12 \mathrm{~h}$ e pode ser utilizada isoladamente ou em associação com 0 ceftazidime ou rifampicina. Tem sido usada freqüentemente como terapia doméstica primária ou se seguindo aos esquemas de antibioticoterapia intravenosa. Seus efeitos colaterais são náuseas e vômitos, cefaléia e desequilíbrio, além de prurido, rash ou erupções cutâneas. A ciprofloxacina pode ser usado por um período longo de até seis meses após o término da terapia intravenosa. Tem havido relato de resistência em torno de $20 \%$ para pacientes tratados por períodos longos (seis semanas ou mais) na terapia para osteomielites. Esta droga não deve ser usada em pacientes abaixo de 18 anos pelo achado existente de artropatia em articulações de animais imaturos em crescimento. Os pacientes devem ser tratados com antibióticos por um período longo de quatro a oito semanas com média de seis semanas. Este prazo, no entanto, é empírico e até o momento não existe um período no qual haja consenso na literatura. Alguns dos critérios propostos de cura eram a cicatrização da pele do CAE e culturas negativas. Mais recentemente a vol- ta ao normal da velocidade de eritrossedimentação foi sugerida como um critério aceitável e seguro. O utros consideram que apenas na volta ao normal da cintigrafia com Gálio-67 é que se pode parar o uso de antibióticos. Um sinal importante de que o tratamento está fazendo efeito é a diminuição ou cessação da otalgia o que algumas vezes sugestiona o paciente parar o seu tratamento. Não há indicação do uso de gotas tópicas de gentamicina ou ciprofloxacina no CAE como nas otites externas difusas, pois é uma via inadequada de administração de antibióticos para uma infecção que se aprofunda na orelha, bem como dificulta a realização de culturas. ${ }^{1,5-7} \mathrm{~A}$ maioria dos pacientes pode ser tratada clinicamente e o papel da cirurgia ainda permanece controverso. 0 debridamento cirúrgico de tecidos desvitalizados e de osso afetado por osteomielite é feito apenas em pacientes nos quais não há resposta ao tratamento clínico habitual. Há alguns sinais que são sugestivos de que haverá maior possibilidade de tratamento cirúrgico como dor progressiva que não cede com a medicação, desenvolvimento de neuropatia craniana e persistência de granulação no CAE. Há relatos de tratamento cirúrgico em que é feita excisão local extensa das cartilagens atingidas e de tecidos desvitalizados e até de ressecção extensa de osso para se ter acesso ao foco primário e assim promover drenagem adequada. ${ }^{1} \mathrm{~A}$ mortalidade continua significante, especialmente no grupo com imunossupressão acentuada. Meyerhoff et al., referem que a mortalidade antes da introdução de carbenicilina e gentamicina era de $37 \%$ e que após, caiu para $23 \%$. A verdadeira mortalidade provavelmente é mais elevada já que muitos casos não são relatados. ${ }^{5} \mathrm{~A}$ recorrência é uma faceta bem reconhecida desta doença ocorrendo em torno de 9 a $27 \%$ dos pacientes e manifestada inicialmente por otalgia insidiosa seguida por cefaléia e dor têmporo-mandibular. Surpreendentemente a otorréia pode ser mínima ou não aparecer, refletindo a predominância da osteomielite da base do crânio como causadora da síndrome clínica. 0 primeiro sinal objetivo é a reelevação da velocidade de eritrossedimentação. 0 diagnóstico e tratamento de pacientes com OEN continuam sendo um desafio para o otorrinolaringologista. Talvez 0 avanço mais significativo nestes anos foi a identificação da OEN como uma entidade clínica distinta e um melhor entendimento de sua fisiopatologia. Se houver um alto índice de suspeição clínico com o diagnóstico precoce, tratamento adequado e colaboração do paciente a mortalidade desta patologia certamente cairá.

\section{APRESENTAÇÃO DE CASO CLÍNICO}

JES, 70 anos, branco, sexo masculino, casado, residente em Recife/PE, com antecedentes de diabetes mellitus tipo II, deu entrada no ambulatório da Disciplina de Otorrinolaringologia da UFPE, em dezembro de 2000, com quadro de otorréia e paralisia facial periférica bilateral. Relatava 
história de queda da própria altura há mais ou menos quatro meses e que evoluiu com otorréia e paralisia facial, inicialmente, à esquerda e após um mês, do início dos sintomas, à direita. Ao exame apresentou secreção fétida e com áreas de tecido de granulação em ambos os condutos auditivos externos, e paralisia facial bilateral grau cinco (classificação de House Brackmann) (Figura 2). Trazia TC de ossos temporais realizada dois meses antes e que evidenciou presença de material hipodenso preenchendo os antros mastóideos e caixas timpânicas bilateralmente com pequenas lesões osteolíticas envolvendo a ponta da mastóide à esquerda. 0 paciente foi internado e os exames de admissão mostraram glicemia de jejum $436 \mathrm{mg} / \mathrm{dl}$ (normal: 70 - $110 \mathrm{mg} / \mathrm{dl}$ ), uréia $24 \mathrm{mg} / \mathrm{dl}$ (normal: 8-20 mg/dl), creatinina 1,2 mg/dl (normal: 0,6-1,2 mg/dl), Na $133 \mathrm{meq} / \mathrm{l}$ (normal 135 - 145 meq/l), K 3,7 meq/l (normal: 3,5 - 5,0 meq/l), hemograma com leucocitose de 18.300/mm3 (normal 5000 - 10000/ $\mathrm{mm} 3$ ) sem desvio à esquerda. Suspeitou-se de OEN e foi iniciado Ceftazidime, um grama intravenoso (IV) de 12/12 horas e Gentamicina, $80 \mathrm{mg}$ IV de 8/8h, correção das taxas glicêmicas com insulina e hipoglicemiantes orais e acompanhamento da clínica endocrinológica. No sexto dia de internamento apresentou ainda secreção pelos condutos auditivos externos e leucograma de $14600 / \mathrm{mm} 3$ sem desvio para a esquerda. 0 esquema antibiótico foi mantido por duas semanas, porém o paciente desenvolveu insuficiência renal aguda (IRA) e a equipe de nefrologia sugeriu trocar o esquema antibiótico pela possibilidade desta intercorrência ser secundária ao uso de aminoglicosídeos ou a uma possível causa infecciosa. 0 esquema antibiótico foi substituído por ciprofloxacino (400 mg IV 12/12) h que foi usado por mais duas semanas e completado para 8 semanas de tratamento da mesma droga por via oral (500 mg de 12/12h). Durante $o$ internamento foi realizada fisioterapia motora para a paralisia facial. A insuficiência renal foi compensada clinicamente. A audiometria tonal mostrou em orelha direita (OD) - perda auditiva mista de grau profundo e em orelha esquerda $(\mathrm{OE})$ - perda auditiva condutiva leve. 0 paciente evoluiu com melhora do quadro clínico e ausência de otorréia e granulação em CAE com membrana timpânica íntegra bilateralmente e de aspecto normal. Realizada cintilografia com gálio após dois meses do início do tratamento, sugerindo processo infeccioso em OD (Figuras 3 e 4). A TC de controle dos ossos temporais após dois meses não mostrava sinais de doença ativa.

\section{COMENTÁRIOSFINAIS}

O s autores descrevem uma apresentação atípica da OEN, o acometimento de ambos ossos temporais e paralisia facial periférica bilateral. Foi feito o diagnóstico diferencial com doenças neurológicas (síndrome do neurônio motor periférico), doenças sistêmicas e secundárias ao trauma, porém todos foram descartados pelos achados clínicos,

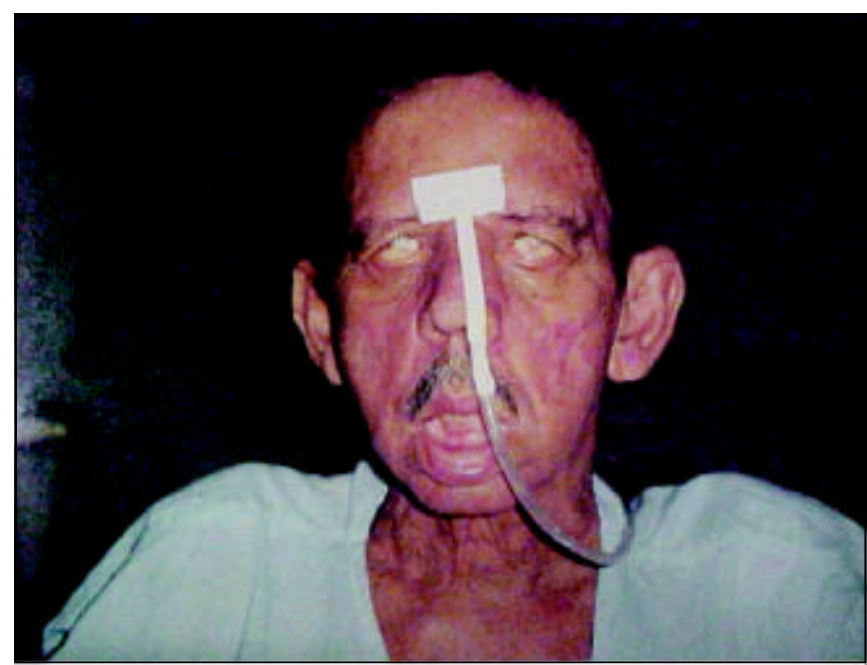

Figura 2. Paciente com Paralisia Facial Periférica bilateral grau $\mathbf{V}$ (House-Brackmann)
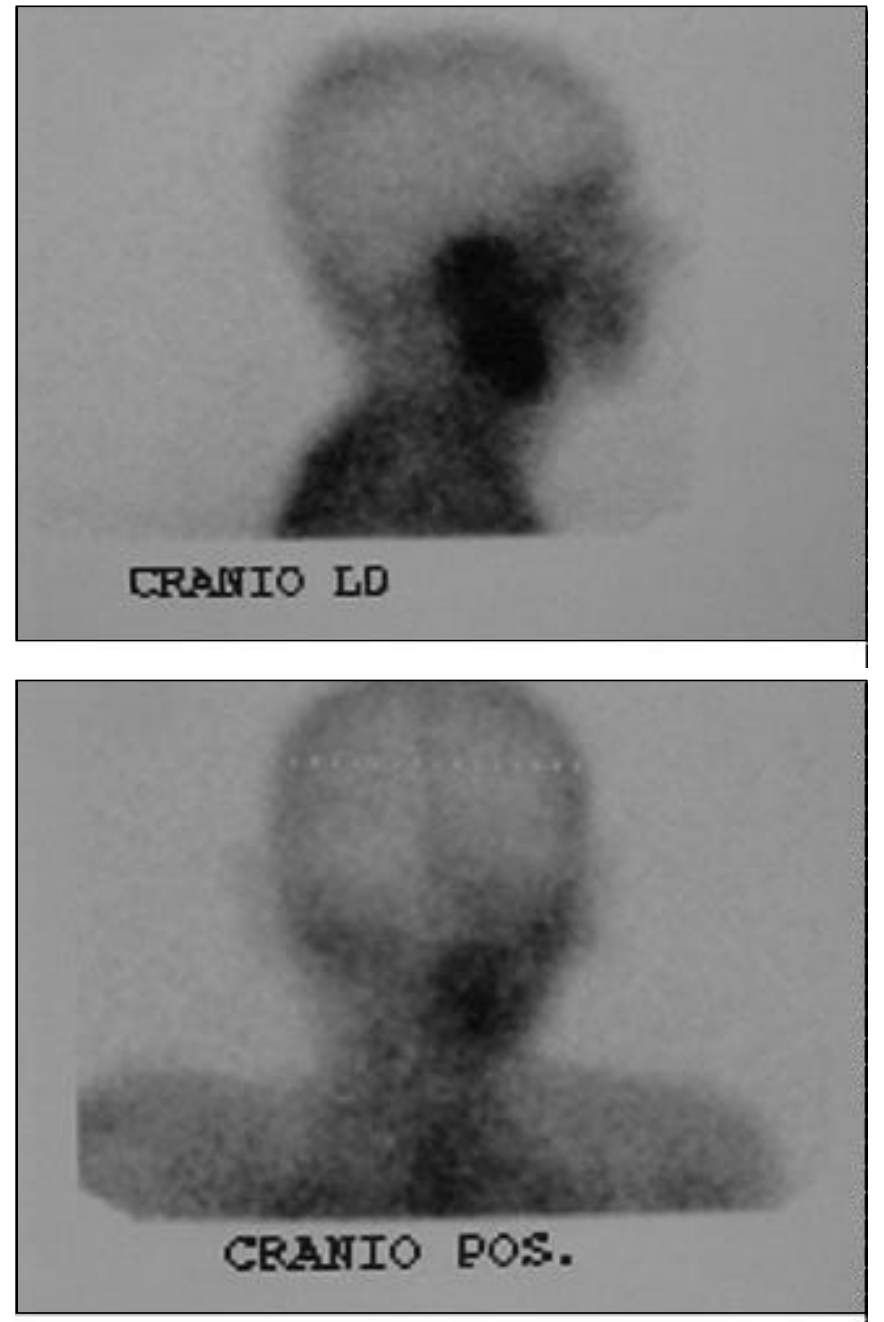

Figuras 3 e 4. Cintilografia com Gálio-67 demonstrando hipercaptação do contraste à nível de Orelha direita 
exames complementares e evolução da patologia, concluindo-se que a paralisia facial era devida ao processo infeccioso nos ossos temporais. 0 ideal seria a realização da cintilografia com Tc 99m e Gálio 67, como também a obtenção do VSH no início do diagnóstico e tratamento. Porém devido à dificuldade de disponibilização da realização destes procedimentos em nosso hospital e em outras instituições conveniadas pelo SUS estes não foram realizados. 0 tratamento medicamentoso proposto foi o uso de uma cefalosporina anti-pseudomonas (inicialmente ceftazidime associado com gentamicina e posteriormente ciprofloxacina) por período de oito semanas, sendo este último utilizado para a continuação do tratamento por via oral. Não houve necessidade de debridamento cirúrgico. Os níveis glicêmicos só foram adequadamente controlados com a melhora do processo infeccioso. Não temos como avaliar com certeza se o resultado da cintilografia com gálio 67 realizado dois meses após o término do tratamento traduz a não melhora do processo infeccioso, pois seria fundamental a comparação com exames iniciais. 0 VSH neste mesmo perío do foi de 8 $\mathrm{mm} / \mathrm{h}$ (normal: masculino $<10 \mathrm{~mm} / \mathrm{h}$ ). Os resultados do VSH normal e a ausência de sinais de osteíte na TC de osso temporal permitem supor que a cura clínica foi al cançada uma vez que há um ano o paciente se encontra livre de doença.

\section{REFERÊNCIASBIBUOGRÁFICAS}

1. Rubin J, Yu VL. Malignant external otitis: insights into pathogenesis, clinical manifestations and therapy. The American Journal of Medicine 1998; 85:391-8.
2. Meltzer PE, Kellemen G. Pyoceaneous osteomyelitis of the temporal bone, mandible, and zigoma. Laryngoscope 1959; 169:1300-16.

3. Strauss M. Current therapy of malignant external otitis. Arc Otolaryngol Head Neck Surg 1990; 102 (2): 174-6.

4. Chandler JR. Malignant external otitis, Laryngoscope 1968; 78:1257-94.

5. Matucci KF, Setzen M, Galantich P. Necrotizing otitis externa occurring concurrently with epidermoid carcinoma. Laryngoscope 1986; 96:264-7.

6. Grandis JR, Curtin HD, Yu VL. Necrotizing (malignant) external otitis: prospective comparison of CT and MR imaging in diagnosis and follow up. Radiology 1995; 196: 499-504.

7. Amorosa L, Modugno GC, Pirodda. Malignant external otitis: review and personal experience. Acta Otolaryngol(Stockh) 1996; 521:316.

8. Ennouri $A$ et al. Les otites externes malignes du duabetique (Malignant external otitis in diabetis patients). Revue de Laryngologie 1989; 110:9-12.

9. Barrow HN, Levenson MJ. Necrotizing "malignant" external otitis caused by Staphylococus epidermidis. Arc. Otolaryngol Head Neck Surg 1992; 118:94-6.

10. Bath AP, Rowe JR, Innes AJ. Clinical records: malignant otitis externa with optic neuritis. The journal of laryngology and otology 1998; 112:274-7.

11. Weinroth SE et al. Malignant otitis externa in AIDS patients: Case report and review of the literature. ENT Journal 1994: 772-8.

12. Al-Shihabi BA. Carcinoma of temporal bone presenting as malignant otitis externa. The Journal of Laryngology and Otology 1992; 106:908-10.

13. Mello LRP et al. Otite externa necrotizante em paciente pediátrico imunodeficiente por desnutrição. Revista Brasileira de ORL 1997; 63 (5): 500-4.

14. Nir $D$ et al. Clinical records malignant external otitis in an infant. The Journal of Laryngology and otology 1990; 104:488-90.

15. Rubin J et al. Malignant external otitis in children. The journal of Pediatrics 1998; 113(6): 965-9. 